\title{
Erratum zu: Kooperationsfaktoren in den Klimaverhandlungen: Eine vergleichende Analyse der Klimagipfel in Kopenhagen 2009 und in Paris 2015
}

\author{
Maximilian Högl
}

Online publiziert: 14. Mai 2020

(C) Der/die Autor(en) 2020

\section{Erratum zu:}

\section{Z Außen Sicherheitspolit 2019}

https://doi.org/10.1007/s12399-019-00782-9

Der Artikel Kooperationsfaktoren in den Klimaverhandlungen: Eine vergleichende Analyse der Klimagipfel in Kopenhagen 2009 und in Paris 2015 von Maximilian Högl wurde ursprünglich am 23.12.2019 ohne „Open Access“ online auf der Internetplattform des Verlags publiziert. Die Autoren haben sich jedoch nachträglich für eine „Open Access“-Veröffentlichung entschieden. Das Urheberrecht des Artikels wurde deshalb 14. Mai 2020 in (C) Der/die Autor(en) 2020 geändert. Der Artikel wird nun unter der Namensnennung 4.0 International (https://creativecommons.org/ licenses/by/4.0/deed.de) veröffentlicht, welche die Nutzung, Vervielfältigung, Bearbeitung, Verbreitung und Wiedergabe in jeglichem Medium und Format erlaubt, sofern Sie den/die ursprünglichen Autor(en) und die Quelle ordnungsgemäß nennen, einen Link zur Creative Commons Lizenz beifügen und angeben, ob Änderungen vorgenommen wurden.

Open Access Dieser Artikel wird unter der Creative Commons Namensnennung 4.0 International Lizenz veröffentlicht, welche die Nutzung, Vervielfältigung, Bearbeitung, Verbreitung und Wiedergabe in jeglichem Medium und Format erlaubt, sofern Sie den/die ursprünglichen Autor(en) und die Quelle ordnungsgemäß nennen, einen Link zur Creative Commons Lizenz beifügen und angeben, ob Änderungen vorgenommen wurden.

Die Online-Version des Originalartikels ist unter https://doi.org/10.1007/s12399-019-00782-9 zu finden.

M. Högl $(\bowtie)$

Deutsches Institut für Entwicklungspolitik, Tulpenfeld 6, 53113 Bonn, Deutschland

E-Mail: maximilian.hoegl@die-gdi.de 
Die in diesem Artikel enthaltenen Bilder und sonstiges Drittmaterial unterliegen ebenfalls der genannten Creative Commons Lizenz, sofern sich aus der Abbildungslegende nichts anderes ergibt. Sofern das betreffende Material nicht unter der genannten Creative Commons Lizenz steht und die betreffende Handlung nicht nach gesetzlichen Vorschriften erlaubt ist, ist für die oben aufgeführten Weiterverwendungen des Materials die Einwilligung des jeweiligen Rechteinhabers einzuholen.

Weitere Details zur Lizenz entnehmen Sie bitte der Lizenzinformation auf http://creativecommons.org/ licenses/by/4.0/deed.de. 